\title{
O Séminaire de Jacques Derrida POR QUATRO CAMINHOS ${ }^{1}$
}

\author{
JacQues Derrida's Seminar through four Paths \\ Ginette Michaud \\ Université de Montréal \\ Montreal, Canadá
}

\section{Resumo}

Quais são as dificuldades de um trabalho de edição dos Seminários de um filósofo como Jacques Derrida? Quais são os riscos com os quais é necessário se defrontar? $\mathrm{Na}$ busca de responder a questốes como essas, tratando especificamente da publicação dos dois volumes do Séminaire La bête et le souverain, o presente ensaio desenvolve uma reflexáo percuciente acerca do arquivo, do luto, da herança e, ainda, sobre a improvisação, a figura do leitor, a partir do modo como se colocam na obra de Derrida. Durante quarenta anos de ensino, o filósofo nos legou uma "obra de pensamento" que pode, agora, ser confrontada, senão transformada, deslocada pelas publicaçôes dos seus Seminários.

Palavras-chave: Derrida; seminários; La bête et le souverain; arquivo; luto; herança.

\section{Abstract}

What difficulties are to be overcome when editing Jacques Derrida's seminars? What risks taken? The essay seeks to provide an answer to these questions, raised by the original French publication of The Beast and the Sovereign's two volumes, through a probing reflection on such topics as the archive, mourning and inheritance - as well as improvisation and the reader's instance - in keeping with the way these questions arise in Derrida's writings. Throughout forty years of teaching, he has left us a "work

\section{Résumé}

Quelles sont les difficultés à surmonter dans un travail d'édition des séminaires de Jacques Derrida ? Quels risques faut-il savoir assumer? Pour répondre à ces questions, mises en rapport avec la publication des deux volumes du Séminaire La bête et le souverain, cet essai développe une réflexion pénétrante au sujet de l'archive, du deuil, de l'héritage, mais aussi de l'improvisation, de l'instance du lecteur, quant à la manière dont ces questions se présentent dans l'œuvre de Derrida. Au cours de ces quarante années d'enseignement, le phi-

\footnotetext{
${ }^{1}$ Uma primeira versão deste texto foi apresentada no Colóquio "Cours et séminaires comme style de pensée. Barthes, Deleuze, Derrida, Foucault", organizado por Guillaume Bellon e Jean-François Hamel, no âmbito das atividades da Équipe de recherche sur l'imaginaire contemporain (ERIC LINT) e de Figura, Centre de recherche sur le texte et l'imaginaire, Montreal, Université du Québec em Montreal, 23 de abril de 2010. Texto disponibilizado on-line em 25 de outubro de 2011, na revista Trahir, em um número consagrado à tradução na obra de Derrida, no seguinte endereço: $<$ http://www.revuetrahir.net/2011-2/trahir-michaud-seminaire.pdf $>$. Em seguida, retomado em meu livro Jacques Derrida. L’art du contretemps. Montréal: Éditions Nota bene, 2014.
} 
of thought" that the publication of his seminars is bound to shift and alter anew.

Keywords: Derrida; seminars; The Beast and the Sovereign; archive; mourning; inheritance. losophe nous a laissé une «œuvre de pensée» que la publication de ses séminaires viendra encore déplacer et transformer.

Mots-clés: Derrida; séminaires; La bête et le souverain; archive; deuil; héritage.

Para dizer as coisas bruscamente, com grandes traços grosseiros, e para atacar o desenho, eis aqui algumas linhas de força: desenhar, designar, assinar, ensinar. Não tem sido difícil, desde sempre, dissociar esses quatro caminhos e apagar a atraçấo que essas operaçôes exercem umas sobre as outras? Não tem sido impossível, desde sempre, pensar a possibilidade do desenho e a responsabilidade do traço sem atraí-lo com um único e mesmo gesto em direção a essas operaçóes, conjuntas e afins a tudo que produz sentido (em direção à própria coisa, ao designatum de toda referência e de todo desígnio), ao mesmo tempo em que se designa ou se projeta a si mesmo (na assinatura), principalmente em relação ao ensino, isto é, à disciplina, à experiência organizada do que se ensina, do que se aprende por si só ou do que se aprende do outro, ensina ao outro, ainda que seja no caso de um ductus genial, e mesmo ali onde a instituição não está mais à altura da experiência inventiva? (DERRIDA, 2005a; retomado em DERRIDA, 2013: 202-203. Grifos de Jacques Derrida).

Como de costume, sempre quando falo ou escrevo, ou fazendo os dois ao mesmo tempo, quando ensino, geralmente, sempre, a cada passo, a cada palavra, sinto ou pressinto, no futuro anterior, a figura inexpugnavelmente espectral de um acontecimento que, suscetível à reinterpretaçáo, poderia, posteriormente, remeter em cena uma cena ainda invisível e imprevisível para quem quer que seja, portanto, remeter em cena, integralmente, tudo o que me terá sido - ditado, soprado, quer dizer, mais ou menos conscientemente, ou telepaticamente, ou sonambulicamente, intimado pelo meu interior, ou ordenado de muito longe, de fora (DERRIDA, 2010).

Antes de seguir algumas pistas do Séminaire La bête et le souveraindois volumes de um mesmo Séminaire e, no entanto, já bastante contrastantes, bastante diferentes entre si, de tal maneira que essa diferença mesma (de tom, de ritmo, de tratamento, de modo de pensar) nos permite vislumbrar, tal qual os quarenta ladróes de Ali Babá que adormecem e começam a sonhar, a que ponto faremos descobertas surpreendentes ao longo deste enorme projeto editorial. Se pensarmos nos quarenta anos de ensino de Jacques Derrida, tesouro de leitura por vir - antes de puxar alguns fios desse rico tecido, gostaria de refletir sobre algumas observaçôes de Marie-Louise Mallet (que coedita com Michel Lisse e comigo os dois volumes do Séminaire) acerca da questáo do trabalho de luto, questáo a cada momento presente no cerne deste trabalho de edição do Séminaire como uma parte outra da obra de Jacques Derrida, como obra póstuma. E "póstumo" - e este já é, de certo modo, o fio vermelho que atravessa todo o segundo volume de La bête et le souverain, essa 
questão da disposição dos restos e da partição entre inumação e cremação - é uma palavra que merece atenção, pois supóe uma linha, uma fronteira entre o "antes" e o "depois", embora esse limite se revele, como qualquer limiar, infinitamente divisível e instável. Por um lado, o póstumo começa bem antes do póstumo, não espera a morte efetiva para fazer parte da obra do vivente e, de algum modo, mordê-la. Como apontou Jacques Derrida, do "começo" (De la grammatologie) ao "fim", em Apprendre à vivre enfin, o "póstumo" já se aplica estruturalmente a todo traço escrito do vivente:

Quando deixo (publicar) "meu livro" (ninguém me obriga), eu retorno, aparecendo-desaparecendo, como o espectro mal educado que não aprendeu a viver. $\mathrm{O}$ rastro deixado por mim significa tanto a minha morte, a por vir ou a que já ocorreu, quanto a esperança de que este sobreviva. Não é uma ambiçáo de imortalidade, é estrutural. Se eu deixo aqui um pedaço de papel, se parto, morro: impossível sair dessa estrutura, é a forma constante de minha vida. Toda vez que deixo partir alguma coisa, que tal traço parta de mim, "escape" de mim, de maneira não-reapropriável, vivo minha morte na escrita (DERRIDA, 2005b: 33-34).

Assim, o póstumo se inicia bem antes do póstumo; de algum modo, já é pré-póstumo (“Eu postumo como respiro”)² (DERRIDA, 1991: 28), já escrevia Derrida, de maneira surpreendente, em Circonfession. Por outro lado, e este é um fato que temos frequentemente observado na recepção imediata, digamos midiática, do primeiro volume do Séminaire, há no póstumo, quando é realmente póstumo, ou seja, pertencendo ao tempo do "depois", uma estranha tendência a não ser percebido "como tal", a apagar-se ou a ser apagado como póstumo precisamente. Denegação, evidentemente, que Jacques Derrida, mais do que qualquer outro, nos ensinou a ler e analisar. Fazemos como se - mas não é justamente os efeitos deste como se, essa poderosa arma de ficção e de fantasma, que Derrida interroga? Talvez... - se o Séminaire La bête et le souverain fosse realmente um livro de Jacques Derrida projetado e assinado por ele, naturalmente e sem mediação. Efeito de "recepção" revelador, sintomático e que pede a reflexão quanto à possibilidade de traçar e manter o limite intacto entre o pré-póstumo e o pós-póstumo... Ou seja, se como escreve Derrida no Séminaire La bête et le souverain, "todos os escritos são póstumos,

\footnotetext{
${ }^{2}$ Significativamente, pois a cena do póstumo é seguida de perto, encenada diversas vezes no discurso deste último seminário, Derrida comenta essa frase na "Sétima seção, de 26 de fevereiro de 2003" (cf. DERRIDA, 2010: 250). Ele retoma igualmente a questão do póstumo na "Oitava sessáo, de 05 de março de 2003", quando ele faz uma hetero-auto-leitura de Pompes funèbres, de Jean Genet e da apoteose da obra como "coroaçáa" - soberania poética - da vida, ao comentar sobre o "Livro ideal, livro sonhado, livro que gostaria de escrever", afirma Derrida por meio das palavras de Genet, esse livro que "toma decisôes é, na verdade, um conjunto de decisôes sobre o póstumo do qual falávamos na última semana, sobre o que se segue à morte, sobre o que vem a seguir, posterus, tendo em vista a posteridade" (DERRIDA, 2010: 312): apoteose premeditada da obra póstuma, mas que tem lugar como gozo no presente, como destaca com notável acuidade Derrida, tanto em relaçáo a Genet como a si mesmo.
} 
cada um a sua maneira, mesmo os que são conhecidos e publicados em vida pelo autor" (DERRIDA, 2010: 294), é patente também - e esta é obviamente a nossa situaçáo agora - que "no interior dessa generalidade do póstumo, no interior do traço que estruturalmente, essencialmente e por vocação destinal se liga ao póstumo ou testamentário, há um enclave mais rigoroso do póstumo, a saber, o que se encontra e se publica somente depois da morte do autor ou do signatário" (DERRIDA, 2010: 294).

Em um texto intitulado "Pourquoi publier les Séminaires de Jacques Derrida”, Marie-Louise Mallet evoca por duas vezes, de modo enfático, a imagem dos “"guardióes do luto por vir' que nos tornamos e particularmente [...] os que entre nós assumiram a responsabilidade da publicação póstuma dos seminários". "Guardiōes do luto" (embora por vir): essa expressão, devido à consonância com o igualmente problemático "dever dememória", continua a ser para mim uma fonte de protesto mudo. Evidentemente, não para negar ou denegar que há luto aí (e reconhecemos que esta frase é assombrada pelo "Há segredo aî̀, de Passions) (Cf. DERRIDA, 1993: 56-61. Grifo do autor), mas sobretudo para interrogar a "guarda" do guardião, dando destaque ao "trabalho", nesta expressão, infelizmente bastante banalizada, "trabalho de/ do luto". Sabemos como Jacques Derrida empenhou-se em trazer à tona esse conceito, destacando a força de atração existente entre as duas palavras, como se pode ver nesta passagem de "À force de deuil":

Quanto ao trabalho - mas que fazemos quando trabalhamos?

Quando trabalhamos sobre o trabalho, sobre o trabalho do luto, quando trabalhamos no trabalho do luto, fazemos já, sim, já, um tal trabalho, suportamo-lo desde o início, o trabalho do luto, deixamos que ele se trabalhe, apoiamo-nos nele, estamos de acordo com ele, concordamos com ele por si, damo-nos esta liberdade da finitude, a mais digna e a mais livre possível.

Não podemos fazer um discurso sobre o "trabalho do luto" sem tomar parte nele, sem nos darmos conta da morte, e sobretudo da própria morte. [...]. Deveríamos poder dizer, já corri este risco, que todo trabalho é também trabalho do luto. Todo trabalho em geral trabalha em luto. De si mesmo. Mesmo quando tem o poder de dar à luz [donner naissance], mesmo e sobretudo quando se premedita trazer à luz [donner le jour] e dar a ver [donner à voir]. O trabalho do luto não é uma espécie entre outras, uma atividade do gênero "trabalho"; de modo algum é uma figura particular da produção em geral (DERRIDA, 2003a: 177-178. Grifo de Jacques Derrida).

\footnotetext{
3 "Pourquoi publier les Séminaires de Jacques Derrida", comunicação apresentada no colóquio "Cinq ans après...", organizado por Maurizio Ferraris, Nápoles, de 7 a 10 de outubro de 2009; publicada em francês nos Annali, "Spettri di Derrida", 2009/V: 404-405 e 407. A expressão "guardiōes do luto por vir" é de Jacques Derrida, que a utiliza no final da última sessão do segundo volume do Séminaire La bête et le souverain (DERRIDA, 2010: 396).
} 
No trabalho de edição, trata-se principalmente de ter direito ao trabalho de luto no duplo sentido do termo, sendo que, desde o início, podemos destacar a potência do tra - de alguma forma, são os quatro caminhos constantemente abertos no Séminaire por Jacques Derrida: travessia, transmissão, trajetória, tradução -, quando se trata de sua experiência (e no sentido mais forte do termo, esta é uma) de ensino. Além disso, Jacques Derrida observou mais de uma vez, especialmente em Fichus, que havia para ele, na vigília, uma outra vigilância além daquela da simples consciência (DERRIDA, 2002b: 18; 20). Gostaria de pensar que nosso trabalho, que visa à transmissão e ao transporte desta parte tão ampla e ainda inexplorada de sua obra, também está ligado a esta palavra, "vigília", mais do que à simples custódia de guardióes ou sentinelas. A vigília, escreve Jean-Luc Nancy, é o que obriga o olhar "à discrição, a regular a luz da lâmpada ou diminuir o brilho da tela", pois o olhar de vigília não é o mesmo do "espetáculo nem da observação nem da inspeção" (NANCY, 2009). ${ }^{4}$ Ao realizar este trabalho de edição, não podemos evitar, como algo inerente ao projeto, os riscos da exposição indiscreta de um corpo de escritura em trabalho, mas o essencial do gesto reside - deveria residir - além: de fato, almejamos que sejam sensíveis não apenas à precisão, à integridade, à sobriedade que, com razão, esperam de nós, mas também a essa leitura atenta e silenciosa, a essa vigília, quando não é tão-somente "vigília atenta" e "monitoramento" (NANCY, 2009). ${ }^{5}$

Segunda observação preliminar: gostaria igualmente de fazer eco ao que Marie-Louise Mallet afirma sobre a dificuldade - sobre nosso "tormento", escreve ela em seu texto - que continua a ser a nossa, mesmo quando o trabalho está bem encaminhado, de reconhecer a legitimidade deste projeto de edição. Certos traços inscritos na própria obra de Jacques Derrida sugerem que talvez - mas o "talvez", por sua vez, não pode ser objeto de garantia ele não tivesse se oposto à ediçấo de seu seminário, ao menos por uma questáo de princípio. Podemos mencionar, nesse contexto, diversos exemplos que parecem aprovar tal decisão. Politiques de l'amitié (1994), por exemplo, "apresenta-se explicitamente como a expansão da primeira sessão do seminário de 1988-1989, sendo que há neste, ainda, vestígios de outras sessōes” (LISSE; MALLET; MICHAUD, 2008: 11). Derrida expressa nitidamente o desejo de "preparar, posteriormente, a publicação de uma série de trabalhos de seminários" (DERRIDA, 1994: 11). ${ }^{6}$ Duas sessões do seminário sobre hos-

\footnotetext{
${ }^{4}$ Agradeço a Jean-Luc Nancy por ter me dado acesso ao texto e me permitir citá-lo.

5 "A vigília mal chega a ser um olhar, é somente o que separa do sono, o que impede de dormir. Ou seja, de ausentar-se, mas sem, no entanto, se voltar em direção a uma presença plena, uma consciência vigilante, como se diz. Velar não é uma vigília atenta. Não é um monitoramento".

6 "Espero preparar, posteriormente, a publicação de uma série de trabalhos de seminários, dentre os quais este vem, na verdade, inscrever-se, para além desta sessão de abertura, que pressupóe assim suas
} 
pitalidade foram revisadas por ele e publicadas em 1997 em De l'hospitalité (DERRIDA; DUFOURMANTELLE, 1997), assim como duas outras sessóes do mesmo seminário apareceram em traduçáo inglesa em Acts of religion, em 2002 (DERRIDA, 2002c). A esse respeito, observa-se que Derrida havia revisado com bastante atenção, de forma pormenorizada, as sessôes em francês (boa parte das frases foi modificada em algum ponto da língua, da sintaxe, da pontuação; substituiçôes de última hora tão significativas quanto enigmáticas), enquanto as sessóes traduzidas para o inglês foram deixadas por ele em estado mais "bruto", demonstrando, de imediato, dois tratamentos distintos de acordo com o idioma. Por fim, terceiro exemplo eloquente (mas, sem dúvida, haveria outros), Derrida reformulou várias sessóes de seu seminário "Le parjure et le pardon" no Cahier de L'Herne: Derrida (MALLET; MICHAUD, 2004), assim como o longo texto intitulado "Versöhnung, ubuntu, pardon, quel genre?”, que corresponde a três sessōes do mesmo seminário, publicado em uma edição da revista Le Genre humain ${ }^{7}$ (DERRIDA, 2004a: 111-156), surgido igualmente em 2004, ano de sua morte. Sem a pretensão de esgotar o assunto, esse levantamento indica que Derrida acreditava que seu seminário constituía uma parte viva, ativa de seu corpus, do qual bebia abundantemente. Vários livros e entrevistas guardam, com esta fonte, este verdadeiro

premissas e seu horizonte. Talvez não seja inútil relembrar aqui o encadeamento com os que o precederam imediatamente, relacionando La nationalité et le nationalisme philosophiques (1. Nation, nationalité, nationalisme [1983-84], 2. Nomos, Logos, Topos [1984-85], 3. Le théologico-politique [1985-86], 4. Kant, le Juif, l'Allemand [1986-87]) e Manger l'autre (Rhétoriques du cannibalisme [1987-88]). E os que vieram em seguida se relacionam com as Questions de responsabilité por meio da experiência do segredo e do testemunho [1989-93]". Talvez estes sejam os argumentos que possibilitam restituir pela publicação do seminário esse "encadeamento" do qual fala Derrida, embora, logo em seguida, ele passe a indicar as razōes que o motivam a publicar, naquele momento, esta "sessão" de Politiques de l'amitié: "Se, por artifício ou abstração, destaco uma dessas muitas sessóes, e somente a primeira por enquanto, deve-se ao fato de que, por razôes aparentemente contingentes, esta deu origem a algumas conferências. Além disso, esta já foi publicada no estrangeiro em versōes levemente diferentes e em geral abreviadas". Essa frase sutil alertava - em uma estratégia perfeitamente derridiana - contra o desejo de "tudo publicar", assim como de "tudo dizer" e, ao mesmo tempo, buscava aliviar a pressão da responsabilidade de quem decidisse, na ausência do autor, editar e publicar os seminários. O fato de Derrida sentir-se obrigado a justificar esse "descolamento" de uma sessão acentua, além disso, a importância que ele atribui ao corpus do qual este provém como corpo textual com a sua própria lógica, suas próprias exigências e restriçôes. Trata-se, portanto, de uma espécie de "dupla injunção": ao mesmo tempo respeitar e restituir uma cadeia de pensamento, seguir esse pensamento em seu desenvolvimento (com toda a complexidade de seu movimento e suas ramificaçóes), ali onde, por aparecer em uma forma oral (conferência, entrevista) ou escrita (livro), esta teve, justamente, que ser interrompida, cortada, "abreviada", mas sem ceder à tentação genealógica, genética ou teleológica (pré-texto, origem, progresso, etc.: aspectos postos em questão no próprio gesto filosófico de Derrida). Entre os seminários e a obra publicada, proveniente daqueles, mas separada pelos ritmos, as decisóes editoriais e traduçôes diferentes, há a dynamis de uma articulação inédita, vital, que possibilita comprender melhor os pontos de interseçấo entre eles e de redesenhar o traçado e o movimento do conjunto da obra.

${ }^{7}$ Na nota, Derrida fala de uma única sessão, levemente modificada, mas há mais três sessōes do seminário "Le parjure et le pardon" (primeira, segunda e terceira sessóes, 1998-1999) que apresentam diversas diferenças estilísticas menores, mas também variantes e acréscimos mais significativos. 
lugar de elaboração de seu pensamento, uma ligação evidente. Dito isso, porém, apesar de sabermos que algumas das sessóes dos seminários foram, às vezes, retomadas por ele em conferências ou tendo em vista alguma publicação - como, por exemplo, em Donner la mort ou, quanto ao seminário que nos ocupa especificamente, em algumas sessóes do Séminaire La bête et le souverain, proferidas em conferências (primeiro volume) ou, ainda, na consagrada a Blanchot (segundo volume) e incorporada por Derrida como punctum final na reediçáo de Parages, em 2003 -, apesar desses precedentes, portanto, que parecem permitir e até mesmo "autorizar" o presente projeto de edição, a verdade é que nenhum "querer-dizer" - e como poderia ser de outra forma na lógica própria incessantemente perseguida pelo autor de La voix et le phénomène? - tem o poder de assegurar a decisão sobre a "expansão"8 da obra póstuma, que só amplia e continuará a ampliar (de impulsionar, phusis e pulsão) os limites da obra publicada, uma obra que sempre foi feita para prescindir do signatário, o que Jacques Derrida não parou de nos relembrar. Esse "tormento" dos editores de Derrida não pode ser apaziguado, mesmo após a responsabilidade assumida - sozinho(a) ou acompanhado(a), há nesta partilha um legado também derridiano - de concluir com êxito (digamos, da melhor maneira possível...) este trabalho. Mais do que isso, poderíamos dizer que é devido à lógica aporética mesma da obra derridiana que permanecemos na indecisão quanto aos méritos do projeto. Pois como um autor (Derrida, mas também qualquer outro), após sua morte, poderia controlar o que diz respeito ao porvir de sua obra? Estamos aqui na prova da soberania impossível: ao mesmo tempo deposição e consagração. Toda a reflexão realizada no Séminaire La bête et le souverain, e não somente nos temas mais explícitos da cremação, da inumação e dos fantasmas de luto que acompanham uma ou outra dessas operaçôes, já coloca em cena, no seu interior, as questóes que nos agitam na "prática" de nosso trabalho. ${ }^{9}$ Mas também - e o tormento não é

\footnotetext{
${ }^{8}$ Em vez da expressão utilizada por Marie-Louise Mallet, "uma extensão indefinida", prefiro a de "expansão infinita", que está em consonância com aquela de trabalho de luto, que Derrida convoca a respeito dos versos de Celan em Aschenglorie, Niemandl zeugt für den/ Zeugen: "Não sei ainda se isso será ou não uma espécie de inscrição. Uma inscrição finita ou uma inscrição em expansão infinita" (DERRIDA, 1995b: 2. Agradeço a Vanghélis Bitsoris, que traduziu o texto para o grego, por ter me dado a versão original, ainda inédita em francês. Esta frase foi suprimida na tradução inglesa).

9 Esta obsessáo quanto ao que o outro fará de meus restos, de "mim", uma vez morto, atravessa todo o segundo volume do Séminaire La bête et le souverain, como observou Marie-Louise Mallet, que cita esta passagem da "Quinta sessão, de 5 de fevereiro de 2003": "Quem é o outro - ou os outros - quando se trata de responder à necessidade de fazer qualquer coisa de mim, de fazer de mim qualquer coisa ou sua coisa a partir do instante em que, como dizem as pessoas, eu tiver partido, ou seja, expirado, estiver morto, extinto, isto é, separado pelo passamento ou pelo trespasse, quando não estarei mais aqui, $d a$, quando estarei, aparentemente, absolutamente indefeso, desarmado, em suas mãos, isto é, como se diz, por assim dizer, morto?/ Como e o que farão no tempo em seguida à morte? [...] / Observem que na questão [...] já parti do pressuposto, sem saber nada sobre o que quer dizer "morte" no sin-
} 
menor - essa parte espectral da obra póstuma (de modo diferente do espectral que já havia na obra publicada em vida) interpela, no entanto, igualmente a sobre-vida e a herança. Como esquecer as questóes que assombram Derrida a este respeito em Apprendre à vivre enfin quando ele evoca a "prova extrema” da ex-apropriação?

Toda vez que deixo partir alguma coisa, que tal traço saia de mim, "escape" de mim, de maneira irreapropriável, vivo minha morte na escrita. Prova extrema: somos expropriados sem saber a quem propriamente a coisa que deixamos é confiada. Quem vai herdar e como? Haverá mesmo herdeiros? É uma questão que pode ser discutida mais do que nunca. Ela me ocupa constantemente. (DERRIDA, 2005b: 33-34).

Evidentemente, a decisão de organizar estes seminários tem tudo a ver com o "aprender a ler" infinito e interminável (quase aproxima, embora de modo diferente, do dito "trabalho de luto") proposto por Jacques Derrida, em um parêntese de alcance sem precedentes, como uma experiência equivalente ou talvez mais importante que a do próprio "viver" ("o leitor aprenderá a ler (a 'viver') aquilo que não aprenderia em outro lugar [d'ailleurs]") (DERRIDA, 2005b: 32). O seminário nos ensina, portanto, a lê-lo de modo diferente, ${ }^{10} \mathrm{a}$ perguntar o que se aprende e o que se ensina da seguinte forma: ler, ou viver, "Isso se pode aprender? Pode-se ensinar? Podemos aprender, por disciplina ou por aprendizagem, por experiência ou experimentação" (DERRIDA, 2005b: 24. Grifo de Derrida), a ler, o que se denomina ler, Jacques Derrida? Esta talvez seja in fine a verdadeira questão que motiva e justifica todo este projeto.

Essas observações se mantêm, assim, à borda, no limite ou no solo de que Derrida fala tão bem na "décima segunda sessão" do primeiro volume do Séminaire, de modo que podemos nos perguntar como organizadores do Séminaire se alguma vez ultrapassamos esse limite ao tomarmos alguma deci-

tagma "quando eu estiver, etc., morto", [já parti do pressuposto] de uma pré-definição da morte, do ser-morto, a saber que estar morto, antes de querer dizer qualquer outra coisa, significa, para mim, estar entregue, no que resta de mim, como em todos os meus restos, estar exposto ou entregue, sem qualquer defesa possível, uma vez mais totalmente desarmado diante do outro, dos outros. E por pouco que eu saiba o que quer dizer alteridade do outro ou dos outros, devo pressupor que o outro, os outros, são precisamente os que podem morrer depois de mim, sobreviver a mim e, assim, descartar o que resta de mim, de meus restos. Os outros, o que são? [...] os outros são aqueles ou aquelas diante dos quais ou das quais estou desarmado, indefeso, o outro é, ainda, o que pode, um dia, fazer de mim e de meus restos, qualquer coisa, uma coisa, sua coisa, quaisquer que sejam o respeito ou a pompa, por vocação fúnebre, com os quais tratará esta coisa singular que se chamam meus restos. $\mathrm{O}$ outro apresenta-se como outro enquanto tal, como aquele, aquela ou aqueles que podem sobreviver a mim, sobreviver a minha morte e agir como bem entenderem, soberanamente, e soberanamente disporem do porvir de meus restos, se houver. / Eis o que quer dizer, o que sempre quis dizer, 'outro'." (DERRIDA, 2010: 187-189. Grifo do autor).

10 “... Devo ensinar-lhes a aprender a me ler a partir das compulsões” (DERRIDA, 1991: 119). 
são, pequena ou relevante, potencialmente mais importante que o que julgamos saber em determinado momento ou ponto textual do corpus ou se, ao contrário, não permanecemos justamente nesta borda a sentir o solo desta frase, deste encadeamento, tremer, mover sob nossos pés.

Essa questão do ponto em relação ao traçado é, de fato, interessante por si só, pois carrega desde o início a questão do methodos, método e caminho, presente em todo o corpus do Séminaire, constantemente preocupado, ou melhor, atravessado, transportado pelo que sustém, isto é, a preocupação quanto ao curso, à progressão, à abertura de um traçado. E, de imediato, é preciso ressaltar que esta não é uma questão secundária, subordinada, mas o desafio filosófico mesmo da différance, ${ }^{11}$ repetido em cada um desses pontos. A respeito dessa pontualidade em relação aos traços gerais, podemos recordar, com Jean-Luc Nancy, que esta aparece em toda topologia/tropologia différantielle ${ }^{12}$ em Derrida:

O ponto, por definição, é sem dimensão. Ele, o traçado, pode abrir as vias mais remotas, mais cheias de curvas, intrincadas, distorcidas mesmo. Mas é sempre traçado a partir do ponto, traçado do mesmo ponto. Um ponto e um labirinto, eis o segredo de uma identidade. De um a outro, contato permanente e deiscência permanente. Por isso, estamos condenados seja a perder um, seja a se perder no outro. Sem dúvida, não nos faltam algumas referências que demarcam uma continuidade, que permitem falar de uma "identidade" -, mas entende - se $a$ priori que nunca reduziremos a natureza infinitesimal do ponto nem o caráter, estritamente falando, irrepresentável do traçado (NANCY, 2010a: 42-43).

Mais do que qualquer outro aspecto, sem dúvida, é esse ponto infinitesimal e o caráter irrepresentável do traçado que nos interessam no Séminaire (tal qual, aliás, está em questão em toda a obra de Derrida). Enfim, o que fascina no curso deste dis-curso é a sua maneira de engajar-se ou de interromper-se em seu trajeto em tal ou qual ponto preciso, seu modo de ser sensível às sobreposiçóes e interseções, às bifurcações e, sobretudo, ao ritmo do pensamento. Darei apenas um exemplo dessa preocupação constante de Derrida quanto à progressão, quanto ao "que nos mantém em movimento"13 (DERRIDA, 1998a: 5) ou em suspense, como ele diz. Os exemplos são numerosos no segundo volume de La bête et le souverain, ${ }^{14}$ no qual Derrida segue os

\footnotetext{
${ }^{11}$ Apesar de haver traduções em português para o termo "différance", cunhado por Derrida a partir da palavra homófona "différence", optou-se por mantê-lo em francês e, assim, preservar o jogo proposto pelo autor e seguido por Ginette Michaud. [N. do T.]

${ }^{12}$ Idem. [N. do T.]

${ }^{13}$ Agradeço a Marguerite Derrida por ter me dado autorização para citar passagens deste seminário inédito.

${ }^{14}$ Vejam um a respeito do "trespasse": "trespassar, prosseguir, retroceder, trata-se de um processo, um percurso, um movimento em curso, ponto de partida ou ponto de retorno; trata-se efetivamente de progresso ou de regressáo, ou de digressáo, de processo, de processus, de procedimento e de modo
} 
passos de Robinson Crusoé em sua ilha, porém o exemplo que citarei encontra-se no seminário "Le parjure et le pardon", que comecei a explorar recentemente. Vejamos uma passagem reveladora deste procedimento [démarche], no duplo sentido do termo dado por Derrida:

Pedindo-lhes desculpas pelos longos rodeios e sobretudo pelo trajeto em ziguezague ou em slalom, trajeto talvez delirante (como devem saber, delirar, delirare, quer dizer "sair do sulco", desviar-se da linha reta, divagar absurdamente - e talvez o perdáo seja uma hipérbole delirante), pedindo-lhes desculpas, então, pelo longo rodeio, principalmente pelo trajeto em ziguezague ou em slalom, pelo itinerário sem itinerário e às vezes delirante que imponho a sua paciência, vou pleitear circunstâncias atenuantes indicando o rumo desse percurso aparentemente errante, na verdade, planetário (como devem saber, a palavra planeta quer dizer astro errante, que vem de uma palavra grega para errância sobre a qual trataremos em Platáo no final da sessão), curso errante; de fato, provavelmente delirante e louco na verdade; vou indicar o rumo provisório destes rodeios, ziguezagues, digressōes, devaneios, delírios, afliçôes por duas marcas fixas, dois pórticos, duas referências estáveis. Santo Agostinho e Rousseau serão estes dois "pórticos". Faz muito tempo que eles estáo entre meus pórticos preferidos, meus loucos. (DERRIDA, 1998b: 2. Grifo de Derrida.).

Essa passagem é realmente interessante do ponto de vista "metodológico", em que "uma 'loucura' deve tomar conta de seu pensamento", ${ }^{15}$ como Derrida sempre defendeu. De fato, reafirma-se a necessidade dupla do ponto (dois "pórticos", "marcas fixas") e do traçado ("rodeios", "percurso errante", "itinerário sem itinerário") descrita por Nancy, assim como a predileção de Derrida pelo acontecimento, ou seja, pelo imprevisível, por tudo que somente pode surgir, mais especificamente acontecer, nestas ou graças a estas "pequena[s] excursão[óes] associativa[s], outro desvio de slalom ou ziguezague" (DERRIDA, 1998b: 7).

Pouquíssimos pensadores, filósofos ou mesmo escritores, e somente os mais arrojados, são capazes de reconstituir alguns dos processos primários do movimento de sua escrita, de seu pensamento em movimento: Derrida, assim como Freud, que jamais hesita em relatar suas incertezas, suas incompletudes, os impasses ou os pontos obscuros que resistem a seus avanços, é um desses raros pensadores. Dele, como de Freud, poderíamos dizer que "o pensamento se origina da abertura a um impulso vindo de profundezas cada vez mais enigmáticas e resistentes à 'análise’ mesma, seja qual for o sentido dado a essa pala-

de proceder, portanto de dispositivos tanto técnicos quanto jurídicos que abandonaram a ordem do que se chama, no sentido corrente e tardio, natureza" (DERRIDA, 2010: 188. Grifo de Derrida).

${ }^{15}$ De acordo com o título desta entrevista em DERRIDA, 1992: 374: "Isto deve ser inventado a cada instante, em cada frase, sem seguro, sem salvaguarda absoluta. Isto é, a loucura, uma certa 'loucura', deve espreitar cada passo e, no fundo, tomar conta do pensamento, como o faz também a razáo". Grifo de Jacques Derrida. 
vra” (NANCY, 2010b: 141). O que é interessante na abertura de pensamento em Derrida é que esta "consiste exatamente em um movimento de acesso, cada vez singular, ao fato de que não há acesso à revelação ou ao senso primordial" (NANCY, 2010b: 141). Como pensamento, "sua regra só pode ser uma forma de diferir sua própria identidade" (NANCY, 2010b: 142). Desse modo, a análise derridiana, como a freudiana, não possui nem método (se tivermos em mente que "methodos" está ligado à ideia de "caminho certo"), nem objeto, nem saber: esta náo cessa "de deslocar-se por meio de suposiçóes ou conjecturas cada vez mais explicitamente aventureiras [...], em busca de modelos menos modelizáveis ou eficazes" (NANCY, 2010b: 142). Isso se torna evidente de imediato, especialmente no decorrer desse curso, pelo seu desvio, seu impulso, sua forma de traçar, retraçar "a retomada do ser, o jogo de forças empregado" (NANCY, 2010b: 142). Acima de tudo, é esse impulso que interessa. Não é por acaso que, no decorrer do intenso trabalho do último ano do Séminaire La bête et le souverain, ao questionar a essência do "walten" heideggeriano anterior a toda diferenciação entre ser e ente, ${ }^{16}$ é precisamente o Trieb, o treiben, o pulsar da pulsão, que Derrida combinará com outro verbo alemão capital em todo este trabalho, tragen. O Trieb - impulso, crescimento, pulsação da pulsão mesma - é o nome encontrado por Freud e relançado com força aqui por Derrida para especificar essa abertura, "esse esforço, e mesmo essa imposição de sentido anterior ou posterior a toda significação", quando a palavra "esforça-se em deixar falar o que precede à própria palavra, à significância em estado nascente", como escreve Nancy a respeito de Freud. E esse impulso no qual somos "como que arrastados pelo que somos responsáveis por carregar" (NANCY, 2010b: 147) é também o da palavra de Derrida neste Séminaire.

\footnotetext{
${ }^{16}$ É absolutamente surpreendente que o último seminário de Derrida - "último" não por alguma visada teleológica, intenção ou decisão deliberada - seja alinhavado a este ponto pela pesquisa desta palavra, "walten", que toda a sua potência permaneceu reservada até a este ponto de seu trabalho (e até às últimas páginas da última sessão, como sua "última palavra”...) e ignorada, afirma Derrida, por todos os críticos de Heidegger: "como podem ver, tarde na minha vida de leitura de Heidegger, acabei de descobrir uma palavra que parece me obrigar a pôr tudo em outra perspectiva. Eis o que acontece e deveria ser pensado sem parar. Se eu não tivesse interessado na problemática da besta $e$ do soberano, estou certo de que a força e o poder regularizador dessa palavra alemá tấo difícil de traduzir, mas que informa, que dá forma a todo texto heideggeriano, não teria me surgido como tal. Da mesma forma que náo apareceu, tanto quanto é do meu conhecimento, a outros" (DERRIDA, 2010: 383. Grifo de Derrida). Michel Lisse relata igualmente a desconstrução onto-teológico-política contida nesta palavra em seu texto "Chaque homme est une île" (LISSE, 2010b: 74-75). Recordemos que em "Un ver à soie" (DERRIDA; CIXOUS, 1998: 85), Jacques Derrida elaborou uma tal cena na qual, até à "última palavra", a palavra manteve, da mesma forma, a potência de uma "revelação" ou de uma "maturação" imprevisível. Ora, é o que acontece efetivamente com "walten", que efetua neste último seminário uma tal cena de leitura, desenvolvendo até à "última palavra", e até ao fim deste traçado de leitura sua potência, seu escopo, de modo táo impressionante como perturbador.
} 
Por outro lado, para abordar o corpus dos seminários por outro ângulo (percebam que eu mesma sigo, nesta apresentação "por quatro caminhos", uma linha pontilhada e em ziguezague), podemos igualmente lembrar, não sem pertinência mas com certa apreensão, as proposiçóes derridianas a respeito do arquivo. Pois mais e melhor do que qualquer um, Derrida teorizou insistentemente acerca das aporias ligadas ao "mal de arquivo", pelas quais este projeto de edição não pode evitar de ser afetado. Derrida, de fato, sempre insistiu sobre a violência constitutiva do arquivo, sendo este (arkhê) o lugar mesmo do exercício de um poder soberano que se manifesta em cada uma de suas operaçóes, que se trate da seleçáo, da conservação ou da rejeiçáo, da supressão/recalque ou mesmo da destruição dos traços arquivados. Tendo em mente essa rica reflexão que não nos deixaria em paz durante as decisões que fomos obrigados a tomar em nome de regras ou de normas editoriais (e como evitá-las?), podemos, contudo, fazer uso de argumentos externos à obra ao colocarmos em dúvida os méritos deste projeto.

Este projeto de edição do Seminário se justifica, igualmente, por razóes externas. Sob o risco de ir (apenas uma vez) contra a vontade de Jacques Derrida que, como sabemos, sempre demonstrou sua aversão perante os efeitos de "geraçáo" e outros amálgamas duvidosos ligados à atualidade, à contemporaneidade, ${ }^{17}$ etc. - efeitos de "geração" que este colóquio induz desde seu título ("Barthes, Deleuze, Derrida, Foucault"), agrupando os nomes desses pensadores em uma categoria "genérica", a de "cursos e seminários", que supostamente seria comum a eles, tornando-os, assim, corpus de "singularidades" irredutíveis -, é claro que toda esta parte do trabalho filosófico de Derrida em forma de ensino nos interessa também pela relação com outros corpus de escritores ou filósofos. A contribuição da obra de Derrida, os efeitos de seu modo de pensar transbordam obviamente seus próprios limites e a parte póstuma de seu trabalho possui um interesse suplementar na medida em que ultrapassa, de alguma forma, a própria obra, atualizando de maneira privilegiada sua "fábrica editorial", ${ }^{18}$ (CORPET, 2002: 16) de acordo com

\footnotetext{
17 "Mas detesto e contesto a imagem que querem cada vez mais difundir quando, na imprensa, tentam ou fingem 'tomar-me' por um 'sobrevivente', e mesmo o único sobrevivente de uma geração que, aliás, não era exatamente a minha (Lacan, Althusser, Deleuze, Foucault, Lyotard, o 'pensamento de 68', ora). Em certo sentido, é verdade, mas em outro, se me permitissem, demonstraria em que medida isso é falso e, no fundo, tal como uma pulsão de morte, pernicioso" (DERRIDA, 2004b: 16; retomado em DERRIDA, 2013: 367-368).

${ }^{18}$ Evocando o "devir póstumo da obra”, Olivier Corpet escreve: "O arquivo remete à obra em movimento, às vezes à custa de uma profunda revisão - como acontece, por exemplo, quando chega a hora das obras ditas completas (outro fantasma editorial e autoral), com seus inevitáveis efeitos de leitura, de recepção e de sentido. $\mathrm{O}$ arquivo torna-se, assim, a condição de uma re-vida da obra, embora, inevitavelmente, isso desloque o estatuto, as linhas (principalmente na partiçáo vida privada/vida pública), modifique suas estruturas e classificaçóes" (CORPET, 2002: 21. Grifo do autor).
} 
a expressão de Olivier Corpet. Essa relação do gênero do seminário com o "methodos" - dis-curso do método, via rupta e (des)orientação, Weg e Umweg do pensamento - é, de fato, constantemente ativada, como disse anteriormente, colocada en abyme e refletida no decorrer do trabalho realizado no próprio seminário, seja por alusões explícitas ao Séminaire de 1929-1930 de Heidegger, no qual o filósofo alemão ensina, do alto de sua cadeira, ex cathedra, seja de maneira mais discreta ou criptografada ao longo do percurso do seminário, inclusive por meio do "como se orientar" kantiano ou da experiência do retorno sentida por Robinson diante da marca, "do traço dos pés descalços que poderiam ser os seus ou de um outro, no caminho que ele tanto pode ter percorrido como ser o caminho de outro" (DERRIDA, 2010: 85).

Entretanto, como, de fato, ler cursos ou seminários? Como a proposta deste colóquio bem o demonstra, de forma adequada, ao salientar a necessidade de interrogar as questôes tanto teóricas quanto práticas, técnicas, retóricas, deontológicas e éticas, que devem ser abordadas em uma perspectiva mais ampla que a da dinâmica própria a cada obra ou autor em particular, podemos nos perguntar o que esta "fábrica" de obra, visando particularmente ao ensino - arquivamento, portanto, da palavra viva -, revela "perpetua[ndo] o acontecimento de uma palavra”. Desde já, é preciso complicar essa proposição, pois, por um lado, no caso do seminário de Derrida, trata-se não da transcrição de uma fala (Lacan, Deleuze), nem de notas ou fichas, nem de "aulas" (Foucault), mas de um texto escrito tendo em vista a fala, portanto, de sua leitura em voz alta em uma certa cena ou dispositivo, levando em conta o público (a este respeito, ressalte-se que não se trata somente de "retórica", no sentido restrito do termo, mas de "um corpo-a-corpo com a língua francesa, um corpo a corpo turbulento mas primordial, [...] no qual tudo o que está em jogo se fixa, no qual o essencial está em jogo"19) (DERRIDA, 2000: 30-31. Grifo de Derrida). Por outro lado, para perturbar o limite daquilo que ocorre aqui entre o que é inscrito ou arquivado e o acontecimento que é produzido pelo arquivamento e que não deve ser confundido com o suporte, o corpo, a matéria do arquivo, seria preciso também convocar a reflexão de Derrida acerca do acontecimento, ele próprio subtraído de uma ontologia da presença pura - porém isso nos levaria muito longe. ${ }^{20}$ Basta dizer que as coisas são mais complicadas do que

\footnotetext{
${ }^{19}$ Nesta passagem, Jacques Derrida marca fortemente a importância, para ele, de "uma atenção constante com certo movimento da frase, em um trabalho, não do significante, mas da letra, da retórica, da composição, do endereçamento, da destinação, da encenação. [...] Trata-se aí de uma referência à francidade da língua, da letra, da retórica, da composição, da cena da escrita" (DERRIDA, 2000: 31).

${ }^{20}$ Cf., entre outros exemplos, a passagem em "Le ruban de machine à écrire", inicialmente elaborada na décima sessão do seminário "Le parjure et le pardon" (1997-1998), na qual Derrida parece propor uma descrição do que produz o acontecimento no próprio seminário ao ressaltar o paradoxo entre a experiência viva do presente e a memória da obra que se institui e constitui: "Dizer assim que a obra
} 
aparentam, pois quando se trata de acontecimento, e mais ainda de acontecimento textual no seminário ou no resto da obra de Derrida, deve-se ter em mente esta proposição que ele mesmo arquivou em sua obra, perturbando justamente a delimitação entre performance, presente e acontecimento: "Uma das [problemáticas de estilos diferentes] que desperta cada vez mais meu interesse diz respeito à antinomia paradoxal da perfomatividade e do acontecimento. [...] O que acontece, por definição, o que advém imprevisível e singularmente zomba do performativo" (DERRIDA, 2000: 128).

Como ressaltam, de maneira pertinente, os organizadores na apresentação deste colóquio, "fundando suas escolhas com base em um certo imaginário do autor do qual publica os seminários, a editora apresenta-se como parte integrante de uma releitura dos grandes pensadores": esta é uma questão, na verdade, bastante interessante, que deve igualmente nos deter sobretudo pelo fato de ser difícil para a "parte integrante" manter a acuidade e a distância para se autoanalisar de modo eficaz... Por ora, direi apenas que os editores da obra de Derrida, assim como os leitores sem dúvida, fazem incessantemente a prova da aporia descrita por ele no seminário "Le parjure et le pardon" e que possui a seguinte forma: trata-se ao mesmo tempo de não tocar e tocar; trata-se, por um lado, de não adicionar à obra $e$, por outro, de não diminuí-la; de respeitar sem trair, de trair para continuar fiel. Risco terrível que enfrenta o editor que se sente previamente inscrito e mesmo prescrito na obra que publica. ${ }^{21}$ Cito apenas uma passagem, extraída desse seminário inédito, na qual Derrida evoca em

institui e constitui um acontecimento é registrar confusamente uma coisa ambígua. Decerto, uma obra é um acontecimento, não há obra sem acontecimento singular, sem acontecimento textual, se realmente se quiser ampliar essa noção para além de seus limites verbais ou discursivos. Mas a obra é o traço de um acontecimento, o nome do traço do acontecimento que a instituíra como obra? Ou a instituição desse acontecimento? / Sem fugir da questão, estou tentado a responder que os dois de uma só vez. Toda obra sobrevivente guarda o traço dessa ambiguidade. Guarda a memória do presente que a instituiu, mas, nesse presente, já havia, quando não o projeto, ao menos a possibilidade essencial desse corte, do corte com vistas a deixar um rastro, um corte intencional de sobre-vivência, desse corte que talvez garanta a sobre-vida, quando não há intenção de sobre-vida. Esse corte é, a um só tempo, uma ferida e uma abertura, a chance de uma respiração - e ele já estava de alguma maneira operando. Marcava, tal qual uma cicatriz, o presente vivo originário da instituição - como se a máquina, a quase-máquina já operasse, antes mesmo de ser tecnicamente produzida no mundo, se posso dizê-lo, na experiência viva do presente vivo" (DERRIDA, 2011: 112. Grifo de Derrida).

${ }^{21}$ Darei um exemplo que se encontra em uma obra publicada quando Derrida estava vivo, mas que se encontra também em uma das sessóes inéditas do seminário "Le parjure et le pardon", não tendo o mesmo efeito da... primeira vez quando o lemos pela segunda vez. O exemplo trata de um "erro" de leitura cometido por Paul de Man, quando, no comentário de sua traduçáo do texto de Rousseau, ele acrescenta um " $n e$ ” expletivo, que introduz, segundo Derrida, uma confusão na qual se "corre o risco de fazer o texto dizer exatamente o contrário do que diz sua gramática, sua máquina gramatical”. Atento a essa "surpreendente operaçáo" que consiste, aqui, em adicionar um "ne" expletivo ao texto de Rousseau e lá omitir da citação "duas pequenas palavras", Derrida demonstra a incidência destes acréscimos ou omissóes, quando se trata justamente da questão "[...] do que acontece aos textos, ferindo-os, mutilando-os, acrescentando-lhes próteses” (DERRIDA, 1998a: 10-11; DERRIDA, 2011: 116 119. Texto levemente modificado). Como os editores de Derrida poderiam esquecer tal advertência? 
termos marcantes esse duplo risco que corre o leitor e que é ao mesmo tempo a promessa e a ameaça de sua leitura - de nossa leitura.

Aqueles que não escutam o testemunho profético, esta atestação, pois o apocalipse é uma atestação, um juramento, um eu assino testemunhal, aqueles que não recebem o testemunho, aqueles que não o subscrevem, não o contra-assinam, não contra-assinam o livro e ainda querem mudar algo nele, adicionar-lhe ou subtrair-lhe algo, aqueles que querem escrever, em suma, escrever alguma outra coisa, a mais ou a menos, seu nome ou em seu nome por exemplo, e náo se tornam,então, irmãos, bem, aqueles serão punidos por Deus, e punidos com a morte, ou seja, cortados do livro, da árvore da vida e da cidade de Deus, da cidade santa. São mesmo as últimas ou antepenúltimas palavras deste terrível Apocalipse, desta terrível revelaçáo (pois “Apocalipse”, como sabem, quer dizer desvelamento, revelação da verdade) [...].

Esta ameaça endereçada àqueles que, em suma, escrevem outra coisa porque não têm fé, não professam nenhuma fé ou aumentam seus signos e sua escrita porque náo póem fé no texto primeiro; a ameaça de um castigo implacável, sem perdão nem misericórdia, é o espaço aberto a todas as inquisiçôes por vir, uma vez que haveria no próprio livro, no qual deve ser professada a sua fé como um testemunho sob juramento, haveria no livro a prescrição como a descrição do castigo que sofrem aqueles que não creem no livro e acrescentam-lhe algo. $\mathrm{O}$ castigo dos descrentes faz parte do livro, está escrito como se diz. Está no programa da prescrição, e é preciso também saber lê-lo (DERRIDA, 1999: 17-18).

Assim - e ouvimos isso muito bem na leitura dessa passagem apocalíptica a respeito da leitura ("editar" é também uma forma de leitura e mesmo de tradução ou de interpretação primeira e primitiva) -, os editores-leitores do Seminário são constantemente atormentados pelo fantasma inscrito no próprio texto, devido ao medo de reduzir, de diminuir "ativamente ou por omissão" (DERRIDA, 1999: 19), diz Derrida, de remover alguma coisa desta obra de pensamento, "de não escutar o testemunho, de mudar algo no livro, inclusive o sentido de incluso, inscrito, prescrito, descrito. Textualmente" (DERRIDA, 1999: 19). Tal é o risco assumido: que este trabalho seja uma "redução diminutiva" da obra, que diminua "o texto ao lê-lo/ escrevê-lo", que faça “menos com mais" (DERRIDA, 1999: 18).

Outra série de questóes que pode e deve ser levantada: como o seminário, este lugar princeps de elaboração de seu pensamento, remete à obra publicada? Como a consolida, a prolonga, mas também altera a sua percepção, recepção, interpretação? Derrida já havia suscitado, a respeito do arquivo de Hélène Cixous em Genèses, généalogies, genres et le génie, o alcance de tais problemas, que podem ser vistos também como os seus, ao observar que estes "são e sempre serão mais agudos neste caso em particular do que em qualquer outro, talvez irremediavelmente sem solução, cooperando, de modo decisivo, no coração 
mesmo da indecidibilidade, com a problematização, a elaboração, a transformação e a renovação de todas essas questôes" (DERRIDA, 2003b: 69). Como a edição dos seminários de Derrida vai influenciar, transformar, deslocar a obra publicada? Visibilidade ou obliteração? Obliteração por subvisibilidade? Sem dúvida, é cedo para dizer e ainda mais prever; porém, em Mal d'archive, Derrida já havia demonstrado como o arquivo an-arquivava ao mesmo tempo o que arquivava, ${ }^{22}$ e este projeto editorial provavelmente não escapará dos efeitos de supressão, não importa o que seja feito para neutralizá-los ou diferi-los. De qualquer forma, trata-se de questões com sérias implicaçóes teóricas que afetam a institucionalização, a estabilização, a legitimidade/conservação/consagração da obra, uma obra escrita que, no caso, tem em vista a situação particular de um ato de fala, daí se torna ainda mais importante não trair, não se afastar do estatuto deste pensamento incerto, em movimento, que, como indiquei anteriormente, tenta se encontrar no momento mesmo em que avança. As questóes levantadas na apresentação do colóquio - "O que pode, além disso, nos ensinar a leitura de um pensamento que se oferece sob o risco da improvisação? De que vale uma análise que não se sujeita a produzir um resultado mensurável, teórico (já teorizado ou facilmente teorizável), mas prefere a 'nuance', o 'comentário', a 'descrição sumária'? E o que pode encontrar nossa época no confronto que esta propóe com seus pensamentos muitas vezes abortados ou abandonados ao longo do caminho?" - certamente podem ser convocadas no caso do seminário de Derrida, mas rapidamente percebemos que estas já são todas pensadas, senão atacadas no interior mesmo do pensamento de Derrida. Por exemplo, no que diz respeito à improvisação, discurso supostamente não premeditado e sem preparação, do qual Derrida sempre questionou a dita naturalidade, insistindo, pelo contrário, em sua copossibilidade com o maquinal, o programa, etc. Evidentemente, Derrida não renuncia, longe disso, à improvisação, permanecendo em alerta, atento ao que pode surgir no "improviso" (literalmente: ao que não se vê chegar); e, por essa razão, decidimos transcrever todos os acréscimos orais significativos, "improvisaçôes” previstas geralmente no próprio texto pelas menções "Comentar" ou "Desenvolver". Porém, devemos lembrar que, como tudo que escreveu e disse Derrida (a palavra oral de suas entrevistas era também escrita), seus seminários são cuidadosamente preparados, com nuances, prudência e atenção em relação aos riscos assumidos. A improvisação, para ele, não se separa jamais da "máquina" textual e o acontecimento, se e quando existe, não se limita tão-somente à improvisação no

${ }^{22}$ Cf. DERRIDA, 1995a: 26. Cf. também DERRIDA, 2002e: 47-48: "A partir do momento que há arquivamento, está em jogo não somente o passado, mas o porvir. $\mathrm{O}$ ato de arquivamento, que se deve manter, é também um ato de amnésia. A amnésia está em ação na memória preservada, no ato que consigna. Na consignação arquivística, há tanto esquecimento (ou não) quanto memória". 
sentido corrente do termo. Além disso, sem subscrever a concepção um pouco mecanicista da teoria formulada mais acima (o que é exatamente um "resultado mensurável” em matéria de pensamento?), o trabalho de Derrida notoriamente nada tem de impressionista nem de desorganizado, pelo contrário: qualquer um que atravessasse um ano de seminário surpreendia-se com a segurança das escolhas, a diversidade dos corpus abordados minuciosamente, o rigor e a coerência das análises que, longe de serem apenas comentários ou de deixarem pontos difíceis em suspenso [en plant] (neste contexto minimalista, é interessante notar que Derrida escrevia constantemente a expressão "deixar plantado" ["laisser en plant"] de acordo com a antiga ortografia do Littré, com um " $\mathrm{t}$ ", como que para deixar esses pontos sensíveis à germinação, ao crescimento por $\operatorname{vir}^{23}$ ), inscrevem-se, pelo contrário, originalmente, em um conjunto, um agenciamento movente, e mesmo em um plano global, mas um plano global e é isso que fascina aqui entre o "desígnio" e o "desenho" do traço derridiano que não é dado com antecedência (nem mesmo como horizonte ou horizonte de expectativa), constituindo-se à medida que empreende sua própria abertura e que, apesar de inúmeros rodeios, digressóes e atalhos, não é jamais aleatório ou casual. Enfim, seria obviamente absurdo afirmar que o seminário de Derrida é desprovido de exposição lógica: ao contrário, sua preocupação pedagógica constante era torná-lo o mais inteligível possível. Em suma, temos: o seminário de Derrida questiona do interior todos os pressupostos que levam à conceitualização das questôes aventadas aqui, como poderíamos demonstrar se examinássemos detidamente os três focos principais em torno dos quais a proposta deste colóquio se concentra ("Dar perenidade ao acontecimento", "Um pensamento incerto" e "Elaboraçẫo de uma comunidade" de leitores). Em cada um desses pontos, o seminário de Derrida, nem confidencial nem magistral, ao mesmo tempo escrito e oral, teatralizado e encenado, de acordo com um dispositivo no qual a figura do leitor/ouvinte não é simplesmente exterior (endereçamento, apóstrofe, invocação cúmplice ou adversativa), mas, sim, intensificada por todo um jogo de vozes internas e íntimas ao discurso (objeçôes, diálogo com o "eu", etc.), coloca, de modo distinto, essas questôes formuladas em termos de oposiçóes rigorosas e desloca, se quisermos, seus termos e pressupostos. O Séminaire La bête et le souverain, portanto, dá uma outra dimensão à própria forma de todas essas questôes, antecipando-as e orientando-as do interior, como se pode ver na epígrafe citada na abertura deste texto.

Em H. C. pour la vie, c'est à dire..., Derrida nos terá advertido - terá de acordo com a modalidade do "futuro anterior" que ele tanto interrogou contra todas as tentaçóes de leitura aprisionadoras (tentação genética, pro-

\footnotetext{
${ }^{23}$ Não há um correspondente em português para a expressão "en plant" que possibilite o mesmo jogo textual expresso neste trecho. [N. do T.]
} 
gramática, efeitos de coerência e de coesão homogeneizantes, teleologia) que consistem em "quer[er], retrospectivamente, ler antes todos os futuros anteriores" da obra, "o que sempre pode ser feito, mas que não podemos nem devemos jamais fazer”, afirma ele (DERRIDA, 2002a: 128). Não é isso, portanto, que deveria nos deter, inicialmente, na leitura de seu seminário - nem "pré-texto", nem "rascunho-em-vista-de...", nem teleologia, nem retrospecção -, mas, sim, a maneira realmente muito mais unheimlich pela qual a antecipação, o ler antecipadamente e sempre antes, ultrapassando Derrida, liga-se ao acontecimento, a uma potência performativa outra. Pois o que é sempre também unheimlich em Derrida é o modo como programa e acaso, cálculo e acontecimento, invenção e demonstração andam juntos. Assim, ao iniciar o seminário, como podia ter uma ideia táo precisa de seu entrelaçamento textual, se este não estava ainda constituído? Por outro lado, o modo de exposição de Derrida, se é rigoroso, minucioso e complexo, não advém do seminário propriamente dito, de caráter quase confidencial, nem tâo-somente do curso magistral, e menos ainda do estilo soberano da "aula", como sugerido no programa de uma sessão consagrada, em 2009, ao Séminaire La bête et le souverain, no âmbito da programação da Citéphilo, ${ }^{24}$ no qual se "aplicava" de maneira lúdica, em Derrida, seu próprio "objeto" de análise:

O professor dramaturgo que é Derrida ministra conferências tão magistrais que a questáo de seu próprio papel de soberano, de professor-soberano, não pode deixar de ser mencionado, mesmo se a energia e a força, às vezes quase brutas, de sua escrita, de suas marcaçóes de território, de seus deslocamentos (de um jeito discreto ou não) [a pas de loup ou pas], fazem-nos sentir que a besta, o animal em açâo, é ele, aquém ou além de tudo o que (não) tem sido dito sobre a (não) chamada besta. ${ }^{25}$

Distanciando-me dessa descrição cômica, mas um pouco fácil demais, que consiste em retornar a questão analisada a quem a desenvolve (o filósofo "preso", "capturado" em "mico de circo"), diria que a contribuiçáo do seminário de Derrida, no relance interpretativo de sua obra, consiste, antes de tudo, "de um ponto de vista epistemológico (...), no esclarecimento da relaçáo do autor com sua obra, uma vez que implica em um dispositivo de escrita que reflete sobre sua própria construção" (LÉGER, 2002: 9). Essa proposição de Nathalie Léger, parece-me, adquire uma ressonância magnífica no caso dos Seminários de Derrida, nos quais se encontra confirmada em cada

\footnotetext{
${ }^{24}$ Citéphilo é uma manifestação anual de filosofia, que compreende uma centena de eventos, conferências, debates, leituras, exposiçóes, organizada pela associação PhiloLille, desde 1997, na cidade de Lille, França. [N. do T.]

${ }^{25}$ Cf. a proposta da mesa-redonda que reuniu Michel Lisse, Marie-Louise Mallet, Thomas Dutoit e eu, na sessão consagrada ao Séminaire La bête et le souverain. Volume I (2001-2002), de Jacques Derrida, Citéphilo, $13^{a}$ edição das semanas europeias de filosofia, "Usages du temps", Lille, 27 de novembro de 2009, em que uma primeira versão abreviada deste texto foi apresentada. Grifo meu.
} 
etapa, semana após semana, de modo vertiginoso, a impressionante energia conceitual mobilizada até mesmo nas ramificações mais sutis e mais refinadas de sua escritura, o que relança toda a potência de seu pensamento, "revelando a estrutura de sua elaboração" (LÉGER, 2002: 9).

$\mathrm{Na}$ verdade, o que gostaríamos de reencontrar nos seminários, no curso do curso, no seu percurso e seu dis-curso, não seria essencialmente isto, e talvez tão-somente isto: o corpo, o corpo do corpus, seu coração/core? Novamente, é Derrida que nos convida a pensar sobre isso, quando afirma a experiência inventiva de sua própria leitura nestes termos:

O que tento fazer, à minha maneira, sem esquecer, tanto quanto possível, o texto escrito, é reencontrar o corpo. Quem é o corpo de Heidegger? Ou de Nietzsche? Isso é o que geralmente foi ignorado. E essa forma de ignorar o corpo é o primeiro gesto de quem escreve. Escrevemos: deixamos os traços no papel, abandonados à publicação, o que é uma maneira de esconder o corpo. Trata-se de reencontrar o corpo - o corpo do corpus, por assim dizer. Não para salvá-lo ou torná-lo novamente presente, mas para saudá-lo sem salvá-lo, saudá-lo ali onde não há mais saudação para ele. Não se trata, evidentemente, de reencontrar o corpo de Platão ou de Heidegger, mas de ver no texto o que é dito do corpo, o que resta do corpo, o que sintomatiza o corpo ou o inconsciente. No fundo, o corpo aqui é a palavra que vem para substituir o insubstituível: no lugar do que não pode deixar de ter lugar. A palavra "corpo", que não utilizo em oposição a espírito, é o que na assinatura é inimitável, insubstituível, singular. Não se deixa substituir; enquanto a escritura consiste, todo o tempo, em substituir. Portanto, a questão é a da substituição do insubstituível. [...] Como um corpo se expóe, expropria-se deixando (partir) sua marca, a partir de sua marca (DERRIDA; CALLE-GRUBER, 2006: 25-26. Grifo de Jacques Derrida).

O que o seminário de Derrida nos oferece de mais valioso habita neste ensinamento do ensino:

Jamais escrevi para o teatro, mas meu sentimento é que, quando escrevo algo, mesmo um texto clássico de filosofia, o que mais me interessa não é o conteúdo, o corpo doutrinal; é a encenação [mise en scène], é a demonstração [mise en espace]. Tenho a impressão que alguém me lê bem quando lê os meus textos universitários, os mais acadêmicos, interessando-se pela demonstração [mise en espace], pela encenação [mise en scène].${ }^{26}$ Esta leitura ainda é rara, mas é a que me interessa, confesso, é a que me importa. Muito mais do que o conteúdo que eu relato (DERRIDA, 2002d: 38).

Para finalizar, gostaria de dar um rápido exemplo, mas bastante eloquente, dessa preocupação com a cenografia, a constituição espacial [mise en espace]

\footnotetext{
${ }^{26}$ Como no campo semântico do teatro, visivelmente acionado pelas citaçôes de Jacques Derrida, a "mise en espace" é tanto uma espécie de representação que não é o espetáculo propriamente dito, uma demonstraçáo menos sofisticada, quanto a área utilizada para representaçáo, optou-se por utilizar termos aproximativos em português de acordo com o contexto em que aparece no ensaio, mantendo-se a expressão em francês entre colchetes. [N. do T.]
} 
discursiva de sua palavra no ensino. Em uma nota na qual apresenta uma sessão do seminário "Le parjure et le pardon", Derrida chama a atenção para o dispositivo de seu seminário, e não somente deste, mas também para a passagem de um seminário a outro (recordemos que cada um dos seminários da EHESS ministrados por Derrida acerca das "Questôes de responsabilidade" dura pelo menos dois, às vezes três anos. Vejamos o que Derrida afirma nesta nota:

O seminário [trata-se do seminário "Le parjure et le pardon", 1998-1999] foi "composto" e mesmo "dramatizado", encenado um pouco como o espaço teatral de um tribunal onde compareceriam, sucessivamente, como testemunhas, quatro homens (e nenhuma mulher) que eram também protestantes (Hegel, Mandela, Tutu, Clinton). Reconheceremos aqui traços e justificativas desta representação. O seminário prolongou-se, nos anos seguintes, em torno da "Pena de morte". Dispositivo análogo: quatro testemunhas, quatro condenados à morte. Porém, desta vez, de religiōes e de sexos - gêneros - diferentes: Sócrates, Jesus, Hallâj e Joana D'arc (DERRIDA, 2004a: 154. Grifos de Derrida).

Nesta perspectiva, podemos pensar que o seminário responde de maneira exemplar a esse desejo de constituição espacial [mise en espace] do pensamento - différance novamente em curso -, efetuando uma cena de leitura tão rara quanto original no corpus já tão vasto de Jacques Derrida.

À guisa de conclusão, acrescentarei um ponto, ainda pensando no que disse anteriormente a respeito de nossa preocupação como editores deste corpo único. Em "Le ruban de machine à écrire. Limited Ink II" - texto que compreendia, originalmente, várias sessóes do seminário "Le parjure et le pardon", de modo que poderemos apreciar as sutis modulaçóes entre os dois estados do texto quando o seminário for editado em sua integralidade -, Derrida nos advertiu longa e antecipadamente contra o risco de apagamento que sempre pode estar em curso no tratamento arquivístico ou editorial. No texto magnífico em que reflete sobre a precariedade, "a vulnerabilidade do documento delével", "a vulnerabilidade deste artefato [que] o expóe precisamente nesse lugar mesmo em que o signatário acautela, conclama, conjura, previne contra o risco do que viria, como ele diz, 'aniquilar esta obra'" (DERRIDA, 2001: 127), ele se debruça sobre a fragilidade do suporte material - uma folha cortada contendo a anteprimeira palavra do manuscrito dito de Genebra das Confissóes de Rousseau - que foi ao mesmo tempo (parcialmente) destruído e salvaguardado, mantendo a inscrição de seu próprio apagamento, e ele enfatiza a que ponto “(...) o documento de arquivo é transformável, alterável, até mesmo destrutível ou, numa palavra, falsificável. A integridade autêntica está em seu corpo mesmo, em seu corpo próprio e único, de antemão ameaçada. Cedo ou tarde, virtualmente, o pior pode lhe acontecer" (DERRIDA, 2001: 127). 
A grande questão, a que nunca se permite perder de vista aqui, é a de seu corpo, do que vamos fazer com seu corpo, para adiar o máximo possível esse "cedo ou tarde".

Tradução do francês de Milena Magalhäes (Doutora em Teoria da Literatura / professora da Universidade Federal de Rondônia)

\section{Referências bibliográficas}

CORPET, Olivier. "Au risque de l'archive". In: LÉGER, Nathalie (Dir.). Questions d'archives. Paris: Éditions de l'IMEC, 2002.

DERRIDA, Jacques. Penser à ne pas voir. Écrits sur les arts du visible (1979-2004). Org. Ginette Michaud; Joana Masó; Javier Bassas. Paris: Éditions de la Différence, 2013.

. Séminaire La bête et le souverain. v. 2 (2002-2003). Org. Michel Lisse; MarieLouise Mallet; Ginette Michaud. Paris: Galilée, 2010.

. "Le dessin par quatre chemins", Annali (Fondazione Europea del Disegno), Milāo: Bruno Mondadori Editori, 2005a.

. Apprendre à vivre enfin. Entretien avec Jean Birnbaum. Paris: Galilée, 2005 b. . "Versöhnung, ubuntu, pardon: quel genre?", Le Genre humain: "Vérité, réconciliation, réparation”, Paris: Seuil, n. 43, nov. 2004a: 111-156.

. "Le survivant, le sursis, le sursaut", La Quinzaine littéraire, Paris, n. 882, ago. 2004b: 1-31.

. "À force de deuil". In: BRAULT, Pascale-Anne; NAAS, Michel (Org.). Chaque fois unique, la fin du monde. Paris: Galilée, 2003a.

. Genèses, généalogies, genre et le génie. Les secrets de l'archive. Paris: Galilée, 2003b. . H. C. pour la vie, c'est à dire... Paris: Galilée, 2002a.

. Fichus. Discours de Francfort. Paris: Galilée, 2002b.

. Acts of Religion. Trad. ing. Gil Anidjar. New York; London: Routledge, 2002c. ."Artaud, oui... Entretien avec Évelyne Grossman”. Europe, Paris, n. 873874, jan.-fev. 2002d: 38.

. "Le futur antérieur de l'archive". In: LÉGER, Nathalie (Dir.). Questions d'archives. Paris: Éditions de l'IMEC, 2002e: 47-48.

"Le ruban de machine à écrire. Limited Ink II". In: . Papier Machine. Paris: Galilée, 2001.

. Quinta sessão. In: LE PARJURE ET LE PARDON, 1999, Paris. Paris: EHESS, 1999.

. Décima sessão. In: LE PARJURE ET LE PARDON, 1998, Paris. Paris: EHESS, 1998a.

. Sétima sessão. In: LE PARJURE ET LE PARDON, 1998, Paris. Paris: EHESS, $1998 \mathrm{~b}$. . Mal d'Archive. Paris: Galilée, 1995a.

Témoignage et traduction. Survivre en poète. Atenas, 9 mar. 1995b. Conferência pronunciada no Instituto Francês de Atenas. 
. Politiques de l'amitié suivi de L’oreille de Heidegger. Paris: Galilée, 1994.

. "L'offrande oblique". In: Passions. Paris: Galilée, 1993.

. "Entre crochets I". In: WEBER, Elisabeth. Points de suspension. Entretiens, choisis et presentés par Elisabeth Weber. Paris: Galilée, 1992: 374.

. “Circonfession”. In: DERRIDA, Jacques; BENNINGTON, Geoffrey. Jacques Derrida. Paris: Seuil, 1991.

DERRIDA, Jacques; CALLE-GRUBER, Mireille. “'Scènes des différences'. Où la philosophie et la poétique, indissociables, font événement d'écriture", Littérature: "La différence sexuelle en tous genres", Paris: Armand Colin, n. 142, 2006: 16-29.

DERRIDA, Jacques; CIXOUS, Hélène. Voiles. Paris: Galilée, 1998.

DERRIDA, Jacques; DUFOURMANTELLE, Anne. De l'hospitalité. Paris: CalmannLévy, 1997.

DERRIDA, Jacques; ROUDINESCO, Élisabeth. De quoi demain... Dialogue. Paris: Fayard/Galilée, 2000.

LÉGER, Nathalie. "Avant-propos". In: 2002.

LISSE, Michael. "Chaque homme est une île”, Magazine littéraire: "Derrida en héritage", Paris, n. 498, jun. 2010: 74-75.

LISSE, Michel; MALLET, Marie-Louise; MICHAUD, Ginette. "Introduction générale”. In: DERRIDA, Jacques. Séminaire La bête et le souverain. v. 1 (2001-2002). Org. Michel Lisse; Marie-Louise Mallet; Ginette Michaud. Paris: Galilée, 2008.

MALlET, Marie-Louise; MICHAUD, Ginette. (Org.). Cahier de L'Herne: Derrida. Paris: L'Herne, n. 83, 2004.

NANCY, Jean-Luc. Identité. Fragments, franchises. Paris: Galilée, 2010a. . L'Adoration (Déconstruction du christianisme, v. 2). Paris: Galilée, 2010 b. "Preface". In: . (non troppo). Paris: 2009, inédito.

Ginette Michaud é professora no Departamento de Literaturas de Língua Francesa da Université de Montréal. É membro do Comitê internacional responsável pela edição do Seminário de Jacques Derrida, do qual coeditou dois volumes (Séminaire La bête et le souverain, Galilée, 2008 e 2010). Coorganizou o Cahier de L'Herne. Derrida (L'Herne, 2004) e dedicou vários livros à obra do filósofo: Tenir au secret (Derrida, Blanchot) (Galilée, 2006), Veilleuses. Sur trois images de Jacques Derrida (Nota bene, 2009), Battements - du secret littéraire e "Comme en rêve..." Lire Jacques Derrida et Hélène Cixous (2 vol., Hermann, 2010). Coeditou recentemente uma coletânea de textos de Derrida, Penser à ne pas voir. Écrits sur les arts du visible (1979-2004) (La Différence, 2013; publicado no Brasil, em 2012, pela EdUFSC) e prepara um segundo volume de textos sobre arquitetura (previsto para 2015). Acabam de ser publicados Appels de Jacques Derrida (com Danielle Cohen-Levinas, Hermann, 2014) e Jacques Derrida. L'art du contretemps (Nota bene, 2014). 